\title{
A Note on the Paperback Edition
}

GERHARD RITTER'S biography of Frederick the Great originated in a series of lectures, which were published with scarcely any revisions in 1936 . In my translation, based on the third edition, published in 1954 , I have tried to convey the hard and precise style that characterizes the German text, while eliminating some of the numerous adjectives and parallel phrases that a lecturer might have found useful for emphasis but which seem unnecessary on the printed page. With the author's agreement I have also excluded the brief introduction and epilogue of the original, since they are addressed specifically to the German reader and to German conditions. Gerhard Ritter died in 1967, shortly after the translation was completed; I shall always remember the kindness and tolerance with which he responded to my questions and suggestions. I am also grateful to Mrs. Fannia Weingartner of San Francisco, to the editorial staff of the University of California Press, and most particularly to Herbert F. Mann, Jr., now of the Oxford University Press, for their help in preparing the manuscript for publication. Some minor changes and corrections aside, the text of the paperback edition is the same as that of the original American edition of 1968 .

Peter Paret

Stanford, California

April, 1974 
